\title{
Testing mechanical characteristics of chestnut stakes used in bed sills for stream restoration
}

\author{
Salvatore Benfratello, ${ }^{1}$ Costanza Di Stefano, ${ }^{2}$ Vito Ferro, ${ }^{3}$ Luigi Palizzolo ${ }^{1}$ \\ ${ }^{1}$ Department of Civil, Environmental, Geospatial and Materials Engineering; ${ }^{2}$ Department of Agronomy and Forestry \\ Sciences; ${ }^{3}$ Department of Earth and Sea Sciences, University of Palermo, Palermo, Italy
}

\begin{abstract}
Using of wood elements for constructing bed sills in Mediterranean streams, where the banks are not protected by tree vegetation, needs an evaluation of biological and mechanical characteristics for evaluating both the wood durability and the effectiveness of the stream restoration project.

Very few studies have dealt both with the decay of mechanical characteristics of wood elements employed for stream restoration works and with the changes over time of physical and chemical wood characters.

In this paper, for a wood and stone bed sill located in a stream having no shaded banks, the changes of physical and chemical characters detected after 12, 18, 24, 30, 36, 42 and 48 months on chestnut stakes are preliminarily recalled. Then, using three chestnut stakes extracted after 96 and 108 months and two unaltered stakes, as reference condition, the mechanical compression tests were carried out. The results of the compression tests for both runs (altered and unaltered stake) allowed to establish the influence of the ageing process on the compressive strength and stiffness of the chestnut wood. Finally, using two chestnut stake extracted after 108 and 120 months and two unaltered stakes, the flexural tests were carried out by a four points scheme (two supporting points and two loading points) according to UNI EN 408-2012 standard.

The results of the flexural tests for both runs (altered and unaltered stake) allowed to establish that the wood ageing process determines the decay of mechanical strength of the material and
\end{abstract}

Correspondence: Vito Ferro, Department of Earth and Sea Sciences, University of Palermo, via Archirafi 20, 90133 Palermo, Italy.

Tel.: +39.091.23897068 - Fax: +39.091.484035.

E-mail: vito.ferro@unipa.it

Key words: Bed sill; wood; degradation; mechanical properties; destructive testing; residual life.

Contributions: the authors contributed equally.

Received for publication: 22 December 2016.

Accepted for publication: 15 April 2017.

(C) Copyright S. Benfratello et al., 2017

Licensee PAGEPress, Italy

Journal of Agricultural Engineering 2017; XLVIII:655

doi:10.4081/jae.2017.655

This article is distributed under the terms of the Creative Commons Attribution Noncommercial License (by-nc 4.0) which permits any noncommercial use, distribution, and reproduction in any medium, provided the original author(s) and source are credited. reduces the bending strength of the chestnut wood. From an applicative point of view, the obtained results showed that after 10 years the mechanical resistance characteristics of the wood stakes are less than those corresponding to the undisturbed reference condition.

\section{Introduction}

Wood elements are widely used as basic structural components of most soil bioengineering structures and stream restoration works (Romano et al., 2016). In this last case wood elements are also arranged to realize a structure, which can be filled by stones, and can be constructed emerging from or leaning against the stream bed. Double-fence sill beds constructed by woods elements and stones are currently located in areas where these building materials are available and low-cost (such as Alpine environments) or for achieving environmental standards requested by state agencies or authorities (Ferro, 2006).

The biological origin of the wood element affects the variability of its physical, chemical and mechanical characteristics and supports the susceptibility to numerous biological and non-biologic agents. Wood is a natural material and its properties can be damaged by many organisms whose proliferation is often aided by the action of chemical and physical processes. These processes determine an environment favourable to the biological component development (Schwarze, 2007). According to Powell et al. (2001), the decay of wood under aerobic conditions (typical of structures emerging from the stream bed) is due to the action of fungi while bacteria are the primary degrading microorganisms acting in oxygen limiting conditions such as for the foundations of a check-dam or for a bed sill.

The effective durability of a wood structure, i.e. the temporal interval in which the structure is able to resist to the design forces considered for its design and is strained by allowable stress, is also affected by the physical/mechanical properties of the structural components and local environmental conditions. Wood is a relatively stiff material and is characterized by an optimal strength if stressed in the direction parallel to fibres while it is flexible and presents a weak strength orthogonally to the fibres. Furthermore, wood resistance to traction stress is greater than that to compression since wood fibres are distinguished by a low longitudinal compressive resistance.

A bed sill can be characterized by a durability greater than a wood check-dam, especially for an environmental condition in which the stream banks are not shaded by vegetation (Andrich and D'Agostino, 2000). The oxygen limited condition, which is present in the zone under the bed stream, hinders the development of rot fungi which are the microorganisms responsible of wood-decay (Zabel and Morrell, 1992; Anselmi and Govi, 1996; Cavalli and D'Agostino, 2000). 
Recent investigations (Burruano et al., 2005, 2008) carried out on stakes of chestnut wood (Castanea sativa, Miller), used for constructing a wood and stone bed sill in a Sicilian stream, demonstrated that the service life-time of a wood structure depends on the resistance of the xylem matrix to the attack of microorganisms. The measurements carried out using chestnut stakes sampled at different times after the sill construction (12, 18, 24, 30, 36 and 42 months) (Figure 1) (Burruano et al., 2008) showed many morphological alterations of the wood. In all tested samples, especially in the upper portion of the chestnut which is the nearest to the bed stream, cracks and xylem discolorations occur. The observation and measurements carried out 24 months after the sill construction (May 2006) evidenced surface erosion of the wood (Figure 2a), some cracks (Figure 2b), inner chromatic alterations (Figure 2c), crusted fungal fructifications (Figure 2d) and spongy tissue of the matrix (Figure 2e) occurred (Burruano et al., 2005). The laboratory tests carried out by Burruano et al. (2008) showed that the distribution of the bacterial and fungal populations is related to the examined portion of the chestnut. In particular in the upper part (40 $\mathrm{cm}$ long), which is the nearest to the stream bed, $50 \%$ of the total number of colonies were isolated while at the end of the chestnut, which is $90-120 \mathrm{~cm}$ far from the bed stream, this percentage is equal to $14 \%$. The highest level of microorganism colonization, detected in the upper part, was associated with an advanced degradation of cortical and xylematic tissues due to the favourable aerobic condition.

Physical, chemical and mechanical (compression, flexural) characterization (Calderoni et al., 2010) is useful for evaluating the level of conservation and serviceability of a wood and stone bed sill. The brief review of the available literature on wood decay topic highlights the poor knowledge on the strength of wood staying inside a soil for a long time.

In this paper, for a wood and stone bed sill located in Tumarrano stream, in Sicily, having no shaded banks, the changes of physical and chemical characters detected after 12, 18, 24, 30, 36,42 and 48 months on chestnut stakes are firstly recalled.

Then, using three chestnut stakes extracted after 96 and 108 months and two unaltered stakes the results of mechanical compression tests are presented.

Finally, using two chestnut stake extracted after 108 and 120 months and two unaltered stakes, the results of flexural tests are discussed.

\section{Materials and methods}

A prototype of wood and stone bed sill, constructed by a wood structure constituted of chestnut stakes $(110 \mathrm{~cm}$ long and having a diameter of $5 \mathrm{~cm}$ ) and filled with stones having a size of $30-40 \mathrm{~cm}$, was realized in Tumarrano stream, a tributary of Platani River in Sicily. Thirty chestnut stakes, similar to the ones used for constructing the wood structure, were infixed in the stream bed upstream the sill. These stakes were extracted at fixed time horizons for carrying out some destructive tests.

In the period May 2005 - May 2008 at different time $t$ values from the sill construction (12, 18, 24, 30, 36, 42 and 48 months) seven chestnut stakes were collected and 10 wood matrix samples were extracted from each stake. Each sample was used for determining, by the method of Van Soest (Goering and Van Soest, 1970) and a Fibertec 4010 equipment, the cellulose and lignin content $(\mathrm{mg} / \mathrm{g})$. The measurement of the wood specific weight was carried out by a cylindrical sample extracted at a distance of $60 \mathrm{~cm}$ from the upper end of the stake.

Two stakes (named A and B), collected from the bed stream after 96 months, the stake $C$, extracted after 108 months, and two undisturbed stakes (named I), as reference condition, were used for carrying out the compression tests. The stakes A and B were 109 and $105 \mathrm{~cm}$ long, respectively, and each stakes had a diameter equal to $5 \mathrm{~cm}$. The two undisturbed (I) stakes were $110 \mathrm{~cm}$ long and had a diameter quasi equal to $5 \mathrm{~cm}$. Another stake (C) was collected from the bed stream, after 108 months, for carrying out the compression tests.

The compression test was performed by a Zwick\&Roell Z600 universal testing machine (maximum allowable load equal to 600 $\mathrm{kN}$ ), driven by TestXpert 11.02 software, available at the material testing laboratory of DICAM Department, University of Palermo. The reference mean area of the stake cross-section, useful for calculating the compressive stress, was measured using an image analysis software and fixing the dimensional scale by means of a digital caliper.

Taking into account that the compression test has to be carried out using samples having a ratio height/diameter equal to 2, samples of each stake having an height equal to $11 \mathrm{~cm}$ were used.

The compression strain was calculated by dividing the applied load, measured by the testing machine, by the mean area of the stake cross-section. The wood sample deformation was calculated by dividing the displacement of the cross-head of the testing machine by the sample length. Notwithstanding this approach usually underestimates the deformation, since it takes into account

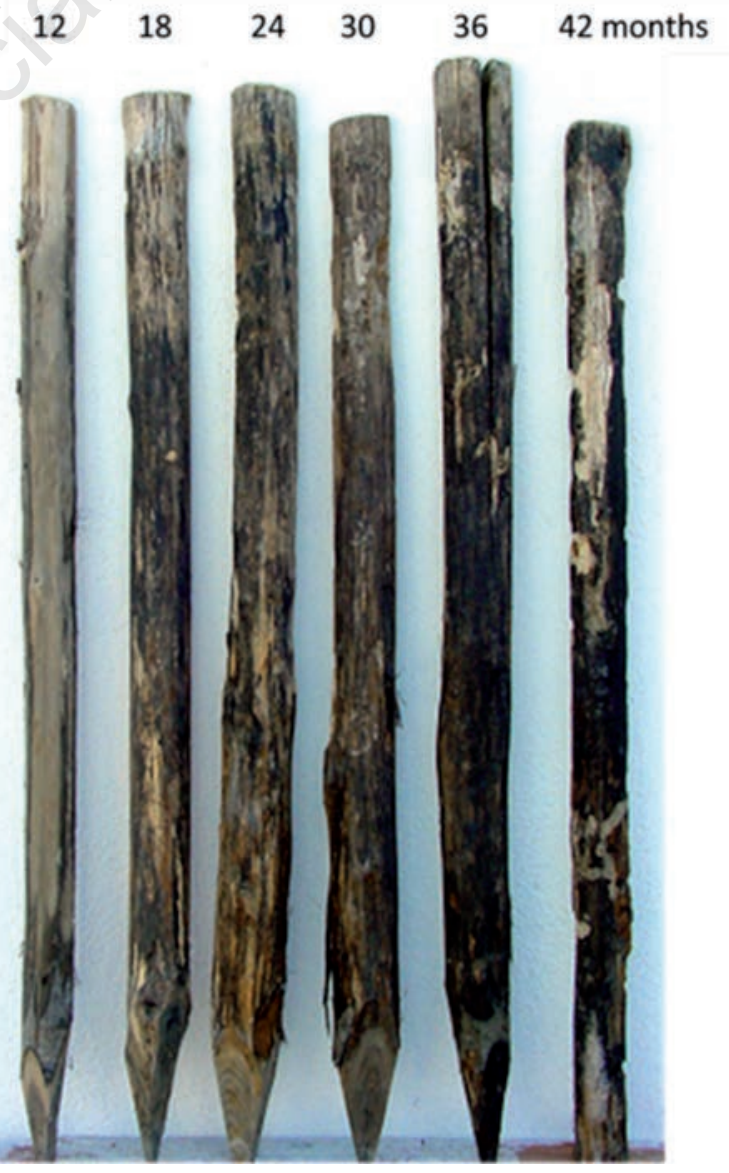

Figure 1. View of the chestnut stakes corresponding at different times from sill construction (Burruano et al., 2008). 
also the strain due to the interaction between the sample and the cross-head, its application is justified by both the intrinsic anisotropy and inhomogeneity of the wood material. Moreover the geometric and surface conditions of many samples did not allow the use of clip-on strain gage.

The compressive strength was identified as the maximum stress value in the stress-deformation experimental curve (Figure 3). The compressive stiffness was calculated as the slope of the straight line connecting the experimental points corresponding to $10 \mathrm{MPa}$ and $20 \mathrm{MPa}$. In the experimental range 10-20 MPa tested wood samples generally showed a linear behaviour.

The bending tests were carried out on both the stake $\mathrm{C}$ and another one (named D), collected after 120 months from the sill construction. This test was performed applying the UNI EN 4082012 standard which requires a four-point bending test (Figure 4) with a sample length greater than $18 d$, being $d$ the mean sample diameter. The tolerance of the distance between the standing points is equal to $3 d$ while the distance between the loading points is equal to $6 d$. Stake D had a length equal to $108 \mathrm{~cm}$ and a diameter equal to $5 \mathrm{~cm}$. As a consequence, the distance between the standing points was fixed to $88 \mathrm{~cm}$ while the distance between the loading points was equal to $30 \mathrm{~cm}$.

According to UNI EN 408-2012 standard, the flexural strength was calculated by the following relationship (Figure 4):

$$
f_{m}=\frac{32 F a}{\pi d^{3}}
$$

in which $F$ is the maximum load applied by the testing machine at the breaking point and $a$ is the distance between a standing point and the closest loading point.

The load was applied to the wood samples by means of an appropriate crossbeam connected to crosshead of the Z600 testing machine using a spherical junction. The test was performed controlling the displacement of the machine mobile part and the maximum load, equal to $2953 \mathrm{~N}$, was reached in 190 seconds.
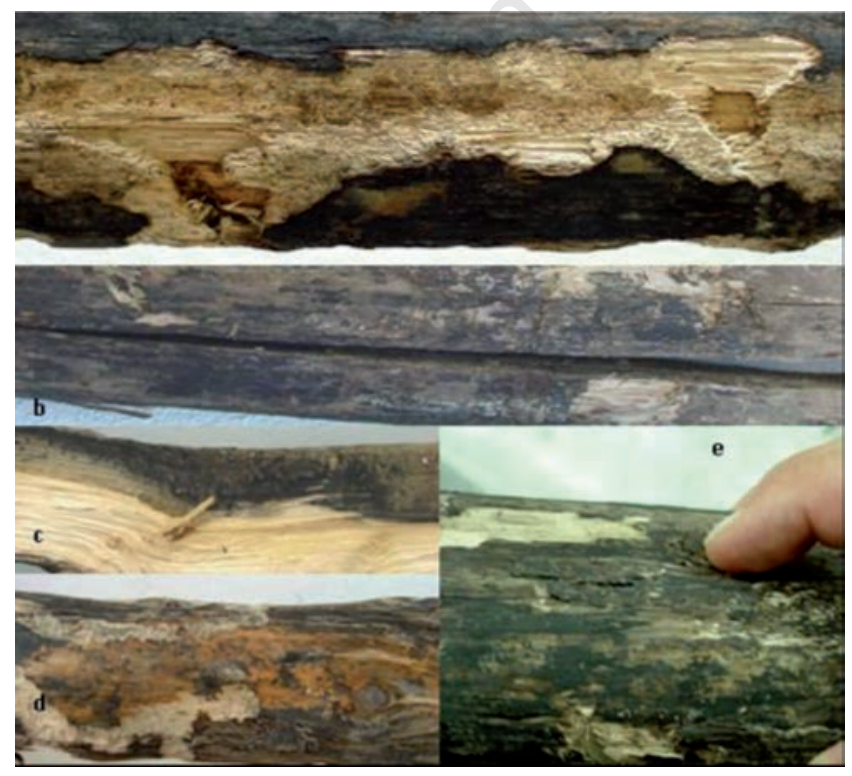

Figure 2. Types of alterations of the chestnut stakes.

\section{Results and discussion}

\section{Testing changes of physical and chemical characters}

The measurements of cellulose showed that the content $(\mathrm{mg} / \mathrm{g})$ is not dependent on the position of the examined sample; in other words, in a sample close to the upper end of the stake, i.e. near the bed stream, a cellulose content similar to the one measured at the lower end was detected. The same behaviour was observed for the lignin content (mg/g) (Alicata et al., 2010).

According to the independence of the cellulose/lignin content on the sample position along the stake, the frequency distribution was examined aggregating the measurements corresponding to different times from the sill construction $(12,18,24,30,36,42$ and 48 months) and distinguishing between the measurements carried out on samples collected at a time less than or equal to 30 months and the ones corresponding to $t$ greater than 30 months. The threshold value $t=30$ months was chosen taking into account that previous research (Burruano et al., 2005, 2008) showed that cracks

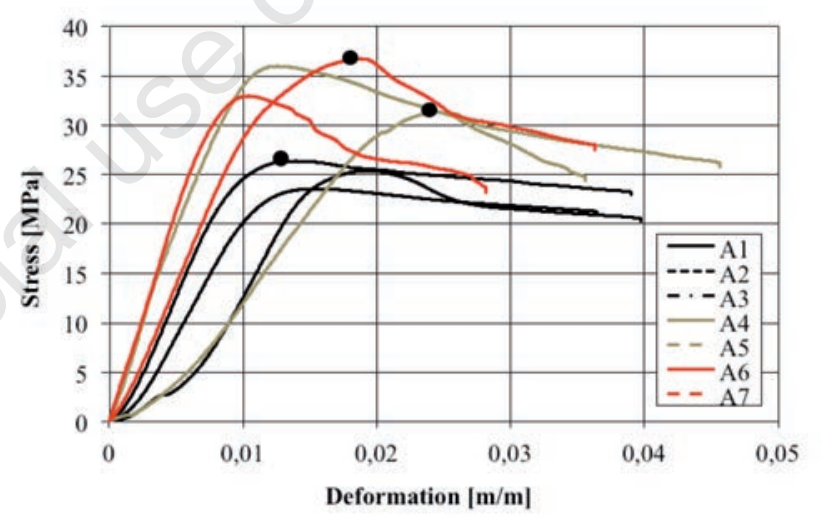

Figure 3. Determining the compressive strength in the stressdeformation experimental curve.

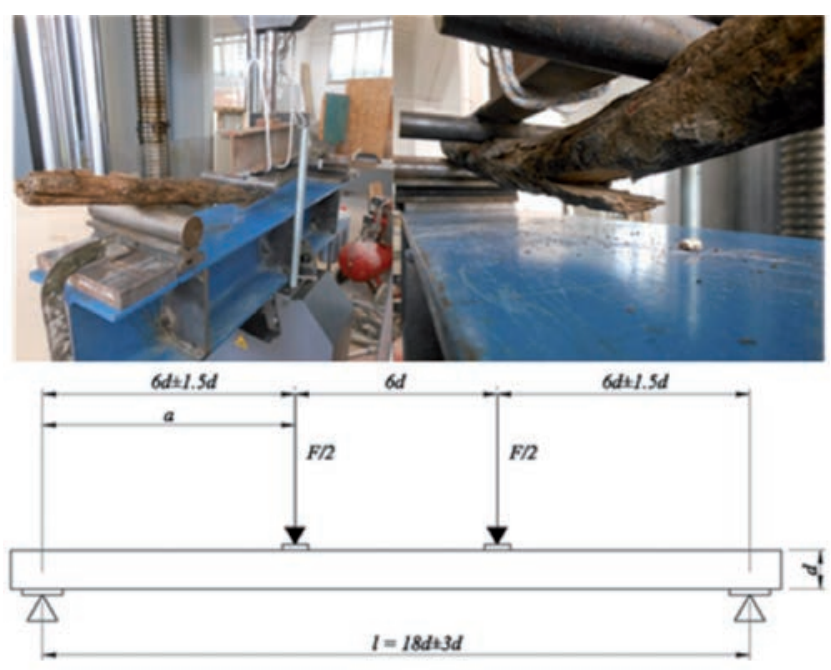

Figure 4. View of the bending test and scheme for calculating the flexural strength according to UNI EN 408-2012 standard. 
of the stakes and xylem discolorations occur after 24 months (Figure 2) and that fungi belonging to the wood-decay group of Basidiomycetes were detected only on samples extracted after 30 months.

According to this hypothesis that the cellulose/lignin content measurements belong to two different statistical populations $(t \leq 30$ months and $\mathrm{t}>30$ months), Figure 5 shows the comparison between the empirical frequency distribution of the cellulose/lignin content and the normal distribution and demonstrates that their content decreases with time $t$.

Table 1 lists the mean value, the median value, the range and the standard deviations of the measured values of cellulose and lignin for the two different time horizons.

The values of the wood specific weight decrease with time (Figure 5) and, in particular, in 48 months a percentage reduction equal to $18.4 \%$ occurred. The mean specific weight of the chestnut

A

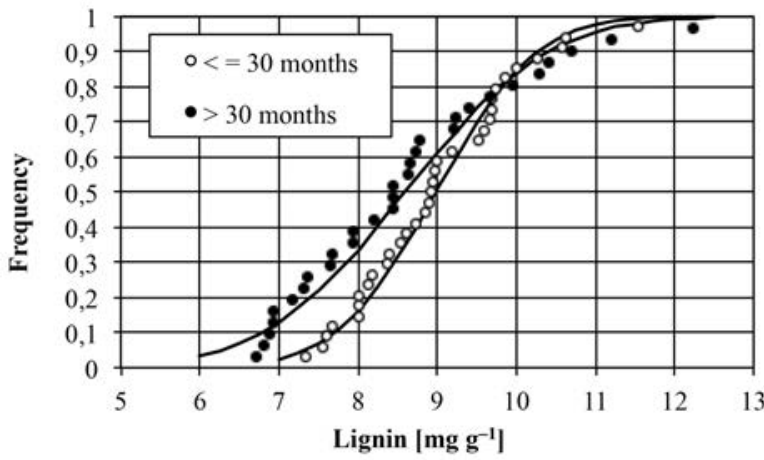

B

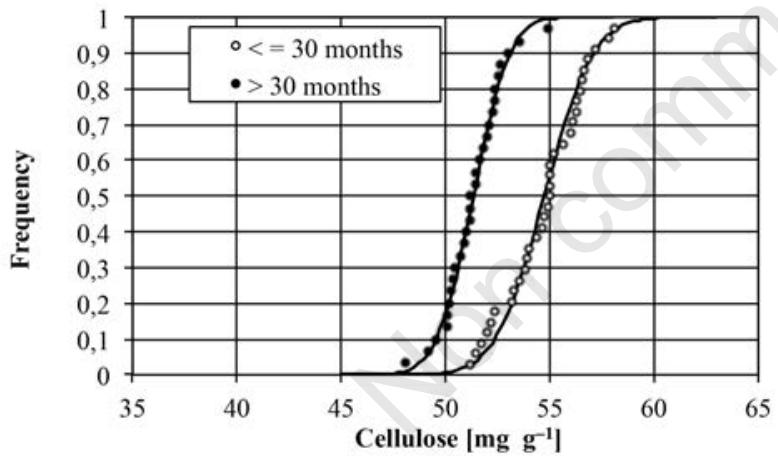

C

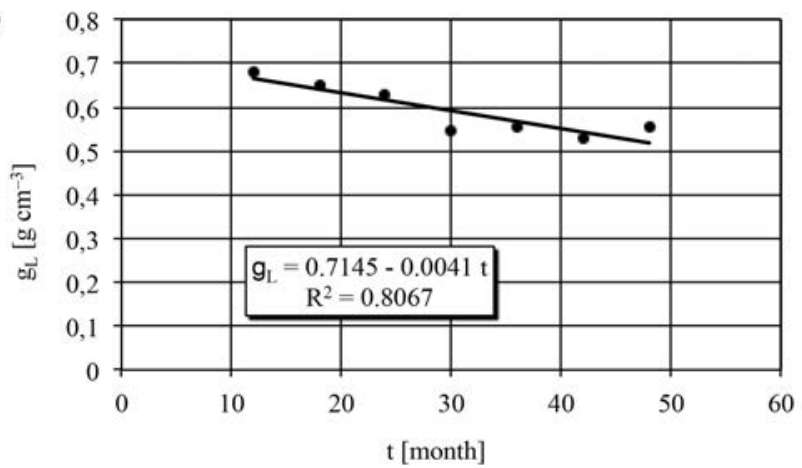

Figure 5. Empirical frequency distribution of the cellulose/lignin content $(A, B)$ and wood specific weight $(C)$ of the investigated chestnut stakes. stake, determined by 7 wood samples, extracted after 96 months was equal to $0.55 \mathrm{~g} \mathrm{~cm}^{-3}$.

In conclusion the chemical (cellulose/lignin) and physical characters (specific weight) change with the progress of the wood degradation process even if after 96 months the wood specific weight falls inside the range (0.54-1.02 $\left.\mathrm{g} \mathrm{cm}^{-3}\right)$ which is typical for chestnut wood (Giordano, 1999).

\section{Testing of compression characteristics of wood elements}

The results of the compressive tests, performed on the samples extracted from stakes A and B (96 months after the construction of the bed sill), C (after 102 months) and two undisturbed (I) stakes, are plotted in Figure 6A. In particular, for each stake (A, $\mathrm{B}, \mathrm{C}, \mathrm{I})$, Figure 6A shows the mean stress-strain experimental curve obtained averaging the ones corresponding to all available samples.

Table 1. Characteristic values of measured content of cellulose and lignin for the two different time horizons.

\begin{tabular}{lcccc} 
& $\begin{array}{c}\text { Mean } \\
\left(\mathrm{mg} \mathrm{g}^{-1}\right)\end{array}$ & $\begin{array}{c}\text { Median } \\
\left(\mathrm{mg} \mathrm{g}^{-1}\right)\end{array}$ & $\begin{array}{c}\text { Range } \\
\left(\mathrm{mg} \mathrm{g}^{-1}\right)\end{array}$ & $\begin{array}{c}\text { Standard } \\
\text { deviation } \\
\left(\mathrm{mg} \mathrm{g}^{-1}\right)\end{array}$ \\
$\begin{array}{l}\text { Cellulose } \\
\mathrm{t}<30 \text { months } \\
\begin{array}{l}\text { Cellulose } \\
\mathrm{t}>\text { months }\end{array}\end{array}$ & 54.7 & 55.0 & $51.2-58.1$ & 1.85 \\
$\begin{array}{l}\text { Lignin } \\
\mathrm{t}<30 \text { months }\end{array}$ & 91.3 & 51.2 & $48.1-54.9$ & 1.39 \\
$\begin{array}{l}\text { Lignin } \\
\mathrm{t}>30 \text { months }\end{array}$ & 8.6 & 8.93 & $7.33-11.55$ & 0.996 \\
\hline
\end{tabular}

A

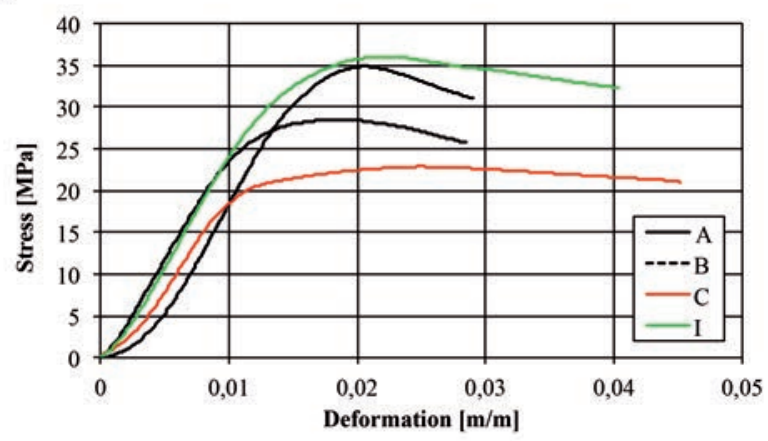

B

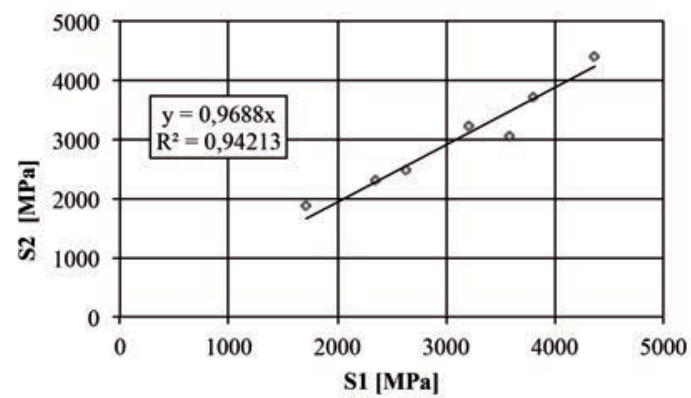

Figure 6. A) Mean stress-strain experimental curve for the investigated stakes; B) relationship between $S 1$ and $S 2$ estimates of the stiffness. 
The compressive strength values of the stake A (23-37 MPa) and $\mathrm{B}(25-42 \mathrm{MPa})$ are close to the ones measured for the undisturbed stakes (32-40 MPa) showing that after 96 months this compression characteristic is close to the condition of the undisturbed stake. Conversely the strength values of the stake C (17-27 MPa) show that the effect of the wood ageing, due to physical and chemical alteration processes, is quite appreciable after 102 months.

In conclusion, after 102 months from the bed sill construction the mechanical characteristics of the chestnut stake are strongly affected by the chemical and physical decay-processes.

In the diagram deformation-stress the range 10-20 MPa, which is represented by a straight line, corresponds to an elastic behaviour of the wood (Figure 6A). For verifying the hypothesis that the compressive stiffness can be calculated as the slope of the straight line connecting the two experimental points corresponding to $10 \mathrm{MPa}$ and $20 \mathrm{MPa}$ (namely S1), i.e. the relationship deformation-stress is linear in the range $10-20 \mathrm{MPa}$, the stiffness S2 corresponding to the slope of the linear relationship of all pairs deformation-stress (which vary from 60 to 120 for each test) in the range $10-20 \mathrm{MPa}$ was also calculated. Figure 6B shows, as an example for the stake A, that the relationship between $\mathrm{S} 1$ and $\mathrm{S} 2$ is a straight line with a slope quasi equal to 1 ; in other words the two estimates of the stiffness are close and the relationship deformation-stress can be assumed linear in the range 10-20 MPa.

$\mathbf{A}$

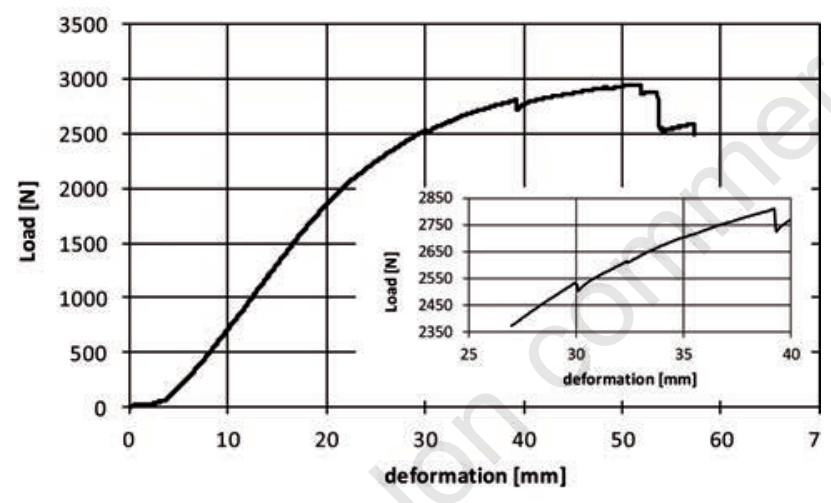

B

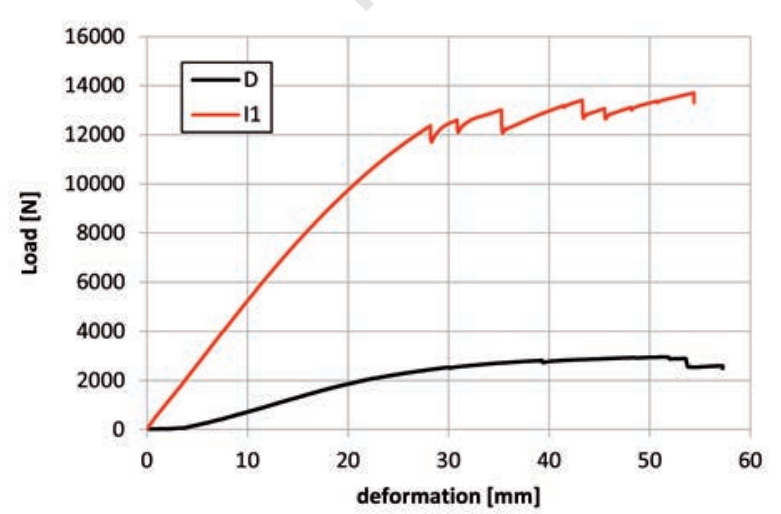

Figure 7. A) Results of the bending test for the chestnut stake D collected after 120 months; B) Comparison between the bending characteristics of stake D and the undisturbed stake I1.

\section{Testing of flexural characteristics of wood elements}

The results of the bending test in the case of the chestnut stake D collected after 120 months from the sill construction are plotted in Figure 7A. This figure clearly shows that, after an initial phase of adaptation between the tested stake and the loading system, the load-displacement relationship is linear until a load equal to 1500 $\mathrm{N}$. Applying equation (1) for a measured value of the breaking load equal to $2959 \mathrm{~N}$ (Figure 7A) a bending strength equal to $69.8 \mathrm{MPa}$ is obtained, which is lesser than the reference strength for chestnut (about $100 \mathrm{MPa}$ ). Figure 7A shows that, after a linear phase, a nonlinear one is present and two local failures, which are pointed out by a sudden load drop, are localized for a load equal to about 2500 and $2800 \mathrm{~N}$. After the maximum load $(2959 \mathrm{~N})$ is reached two further local failures occur and the second one corresponds to the stake break.

The break did not involve all the stake cross-section (Figure 4) and, at the end of the unloading phase of the bending test, the sample get back almost all the deformation occurred during the test. In order to evaluate the wood-ageing effect on the bending behaviour, the same bending test was carried out on an undisturbed stakes (namely I1). The main characteristic of this stakes is length equal to $110 \mathrm{~cm}$ and mean diameter equal to $6.1 \mathrm{~cm}$. A distance between the standing points equal to $92 \mathrm{~cm}$ was used and a distance between the loading points equal to $30 \mathrm{~cm}$, as for the bending test of the stake D, was applied. The maximum applied load (13707 N) has been reached in 334 seconds and the corresponding bending strength is equal to $94.2 \mathrm{MPa}$, very close to the literature value. Figure $7 \mathrm{~B}$ shows that the bending characteristics of stake D are worse than those of stake I1: the maximum load of stake D is 2953 $\mathrm{N}$ while for the stake I1 is equal to $13707 \mathrm{~N}$ (reduction of the maximum load equal to $78 \%$ ); the bending strength of stake I1 is equal to $94.2 \mathrm{MPa}$ while for the stake $\mathrm{D}$ is equal to $69.8 \mathrm{MPa}$, with a percentage reduction of $26 \%$.

This investigation also demonstrated that the bending characteristic of a stake collected after 120 months are worse than those of the undisturbed stake.

From an applicative point of view, these results show that after 10 years the mechanical characteristics of the wood stakes are appreciably less than those corresponding to the reference condition (undisturbed chestnut stake) and, in particular, the worst effects concern the bending characteristics.

\section{Conclusions}

Wood is a natural material and during its life is subjected to biological degradation phenomena related to environmental conditions. Biological and non-biologic external agents can damage wood limiting the service life-time of wooden structures for stream restoration.

In this paper, the decay of mechanical characteristics of chestnut stakes employed for stream restoration works was studied. The physical and chemical characters were detected by chestnut stakes, used for constructing a bed sill, collected at know time horizons (12-48 months). The measurements showed that the chemical characters (cellulose/lignine) decrease with time while the specific weight after 96 months fall inside the range $\left(0.54-1.02 \mathrm{~g} \mathrm{~cm}^{-3}\right)$ which is typical of chestnut wood.

The results of the compressive tests demonstrated that after 102 months the measured strength values (17-27 MPa) are appreciably less than the reference values (32-40 MPa) corresponding to an undisturbed chestnut stake. 
Furthermore, the results of the bending test performed on a chestnut stake collected after 120 months showed the flexural characters (maximum applied load equal to $2953 \mathrm{~N}$ ) of this stake are worse than those (maximum applied load equal to $13707 \mathrm{~N}$ ) corresponding to the undisturbed chestnut stake condition.

Further field investigation will be planned for studying the effect of wood ageing processes when chestnut stakes are used for constructing check-dams.

\section{References}

Alicata M.L., Burruano S., Ferro V., Torta L. 2010. Alterazioni delle caratteristiche fisico-chimiche of chestnut stakes in Mediterranean areas. Quad. Idron. Montana 29/2:273-84.

Andrich A., D'Agostino V. 2000. Durabilità ed economia degli interventi. In: A. Andrich and V. D'Agostino (Eds.), Le opere in legno nella sistemazione dei torrenti montani. Agenzia Regionale per la Prevenzione e Protezione Ambientale del Veneto (ARPAV), Arabba (BL), Italy, pp 123-135.

Anselmi N., Govi G. 1996. Patologia del legno. Edagricole, Bologna, Italy.

Burruano S., Ferro V., Torta L. 2005. Possibilità di impiego di soglie in legname e pietrame in ambiente mediterraneo. Quad. Idron. Montana 25:261-70.

Burruano S., Ferro V., Torta L. 2008. Sperimentazione di laboratorio e di pieno campo sull'impiego di soglie in legname e pietrame in ambiente mediterraneo. Quad. Idron. Montana 28:251-61.
Calderoni C., De Matteis G., Giubileo C., Mazzolani F.M. 2010. Experimental correlations between destructive and nondestructive tests on ancient timber elements. Engine. Struct. 32:442-8.

Cavalli A., D'Agostino V. 2000. Il materiale strutturale. In: Andrich, A., D'Agostino, V. (Eds.), Le opere in legno nella sistemazione dei torrenti montani. A. Andrich and V. D'Agostino (Eds.), Le opere in legno nella sistemazione dei torrenti montani. Agenzia Regionale per la Prevenzione e Protezione Ambientale del Veneto (ARPAV), Arabba (BL), Italy, pp 5-26.

Ferro V. 2006. La sistemazione dei bacini idrografici - II edizione. Ed. McGraw-Hill, Milano, Italy.

Giordano G. 1999. Tecnologia del legno. Ed. UTET, Torino, Italy. Goering H.K., Van Soest P.J. 1970. Forage fiber analysis (apparatus, reagents, procedures and some applications). Agriculture Handbook N. 379, United States Department of Agriculture (USDA), Washington, DC, USA, pp 1-20.

Powell K.L., Pedley S., Daniel G., Corled M. 2001. Ultrastructural observations of microbial succession and decay of wood buried at a Bronze Age archaeological site. Int. Biodeterior. Biodegrad. 47:165-73.

Romano N., Lignola G.P., Brigante M., Bosso L., Chirico G.B. 2016. Residual life and degradation assessment of wood elements used in soil bioengineering structures for slope protection. Ecol. Engine. 2016;90:498-509.

Schwarze F.W.M.R. 2007. Wood decay under the microscope. Fungal Biol. Rev. 21:133-70.

Zabel R.A., Morrell J.J. 1992. Wood microbiology. Decay and its prevention. Academic Press, San Diego, USA. 